\section{Readiness of health facilities to deliver safe male circumci- sion services in Tanzania: a descriptive study}

\section{Frank Mosha, Mwita Wambura, Joseph R. Mwanga, Jacklin F. Mosha, Gerry Mshana, John Changalucha}

National Institute for Medical Research, Mwanza, Tanzania

\section{Abstract}

Assessing the readiness of health facilities to deliver safe male circumcision services is more important in sub-Saharan Africa because of the inadequacy state of health facilities in many ways. The World Health Organization recommends that only facilities equipped with available trained staff, capable to perform at least minor surgery, able to offer minimum MC package and appropriate equipment for resuscitation, and compliant with requirements for sterilization and infection control should be allowed to deliver safe circumcision services. A cross-sectional study using quantitative data collection technique was conducted to assess the readiness of the health facilities to deliver safe circumcision services in selected districts of Tanzania. All hospitals, health centres and $30 \%$ of all dispensaries in these districts were selected to participate in the study. Face-toface questionnaires were administered to the heads of the health facilities and to health practitioners. Overall, 49/69 (59\%) of the facilities visited provided circumcision services and only 46/203 (24\%) of the health practitioners performed circumcision procedures. These were mainly assistant medical officers and clinical officers. The vast majority - 190/203 (95\%) - of the health practitioners require additional training prior to providing circumcision services. Most facilities - 63/69 (91\%) had all basic supplies (gloves, basin, chlorine and waste disposal) necessary for infection prevention, 44/69 (65\%) provided condoms, HIV counselling and testing, and sexuallytransmitted infections services, while $62 / 69$ (90\%) had the capability to perform at least minor surgery. However, only 25/69 (36\%) and $15 / 69(22 \%)$ of the facilities had functioning sterilization equipment and appropriate resuscitation equipment, respectively. There is readiness for roll out of circumcision services; however, more practitioners need to be trained on circumcision procedures, demand forecasting. Sterilization equipment for infection prevention and resuscitation equipment should also be made available.

\section{Introduction}

Male circumcision (MC) has been shown to considerably reduce the risk of sexually acquired HIV infection., ${ }^{1,2}$ Randomized controlled trials have shown that circumcision reduces the risk of HIV acquisition by $60 \% 0^{3-5} \mathrm{~A}$ sub-analysis of 10 African observational studies found a $71 \%$ reduction in HIV acquisition among higher-risk men in $2000 .^{2}$ Similar findings were observed after controlling for potential confounding factors in a 2002 update in which the results of 28 studies plus the 10 studies were considered. ${ }^{6}$ Circumcision has also been shown to have other benefits. These include: a decreased risk of urinary tract infections in children; ${ }^{7}$ a reduced risk of some sexually transmitted infections (STIs) in men (especially ulcerative diseases like chancroid and syphilis) $;, 9$ furthermore, randomized controlled trials have shown that MC reduces the risk of HIV transmission from women to men; ${ }^{3,10}$ protection against penile cancer, if the circumcision is done in the neonatal period; ${ }^{11,12}$ and a reduced risk of cervical cancer in female sex partners. ${ }^{13}$ Modelling studies suggest that universal MC in sub-Saharan Africa (SSA) could prevent 5.7 million new cases of HIV infection and 3 million deaths over 20 years. $^{14}$ Therefore, the World Health Organization (WHO) recommends MC as an additional intervention against HIV infection for countries with high prevalence of HIV infection and lower levels of MC. Many countries in SSA have either introduced or are in now rolling out MC programs. ${ }^{15}$ Prior to rolling out MC programs, it is important for countries to assess the capacity/readiness of health facilities in provision of safe circumcision services. This assessment is crucial for SSA countries because of the weakness of the health systems: ${ }^{16}$ for instance, most facilities lack surgical equipment and other necessary equipment, space (minor theatre, rooms), and so forth. In addition, if MC is not done properly, it can result into adverse events. For example, in a Kenyan study it was observed that bleeding and infection were the most common adverse effects. This study also showed that practitioners lacked appropriate knowledge, training, instruments and supplies. ${ }^{16}$ This paper reports findings from the assessment of the readiness of health facilities to provide safe MC in selected regions in Tanzania and it provides the literature with some empirical evidence on the issues that may adversely affect the scale-up of MC for countries considering MC roll-out.

\section{Materials and Methods}

This study was conducted as part of the sit-
Correspondence: Frank Mosha, National Institute for Medical Research, P.0. Box 1462, Mwanza, Tanzania.

Tel. +255.28.2500399 - Fax: +255.28.2500654

E-mail: fmosha2002@yahoo.co.uk

Key words: male circumcision, HIV infection, health facilities, Tanzania, Africa.

Acknowledgments: we would like to thank the Government of Tanzania which funded this work through the Ministry of Health and Social Welfare and the National AIDS Control Programme. We are profoundly grateful to the regional authorities of Mara, Kagera and Mbeya and the district authorities of Tarime, Bukoba rural and Ileje for their support. We are also grateful to the National Institute for Medical Research for allowing us to publish the study findings. We wish to extend our gratitude to all study participants from the three districts for their valuable information and time. Finally, we thank the fieldworkers, who ensured that the work was carried out to the highest standard, and our data managers, Jonas Aswile and Baltazar Mtenga, who, were instrumental in processing the data for analysis.

Contributions: MW, JFM, JRM, JC, design of the study; GM, FM, MW, JRM, JFM collection and analysis of quantitative and qualitative data; JC, editorial input. All authors read and approved the final manuscript.

Conflict of interests: the authors declare no potential conflict of interests.

Funding: the work was supported by the Ministry of Health and Social Welfare and the National AIDS Control Programme (Government of Tanzania).

Received for publication: 10 January 2013. Revision received: 30 January 2013.

Accepted for publication: 2 February 2013.

This work is licensed under a Creative Commons Attribution 3.0 License (by-nc 3.0).

(C) Copyright F. Mosha et al., 2013

Licensee PAGEPress, Italy

Healthcare in Low-resource Settings 2013; 1:e9 doi:10.4081/hls.2013.eg

uation analysis study in Ileje, Tarime and Bukoba rural districts of Mbeya, Mara and Kagera regions of Tanzania, respectively. To assess the readiness of facilities in a traditionally circumcizing population to provide safe medical MC, Tarime district was selected randomly to participate into the study. Likewise, Ileje and Bukoba rural were selected to learn the capacity of facilities in traditionally noncircumcizing area to provide safe medical MCs. The study aimed to assess the availability and acceptability of circumcision services in health facilities, the procedures for medical circumcision (any pre-operative care, surgical 
procedures, and post-operative care) in clinical set-up, the barriers for medical MC (costs of the procedure, competency of health practitioners, availability of equipment, supplies and consumables for safe circumcision), and the training needs.

The detailed methodology has been explained elsewhere. ${ }^{17}$ In summary, a list of all facilities in the study district was generated stratified by residence (urban, roadside centre, and rural). From the list, all hospitals and health centres and $30 \%$ of the dispensaries in each strata were included in the study. For each facility in the study, a performance checklist and two questionnaires were used to collect information. One questionnaire was administered to the person in-charge of the health facilities to collect information on the number of circumcisions carried out by the health facility per year, age at circumcision, availability of working equipment, supplies and skills required for the operation, cost of the service, and the ability to recoup costs and to meet an increased demand for services. The second questionnaire was administrated to healthcare workers who collected information on the healthcare workers' knowledge and opinions about circumcision practices at the local health facility.

Health service providers' number, skills level and abilities to perform circumcision were measured using a performance checklist which included, among others: infection prevention (use of sterile disposable equipment and protective gears for providers), pre- and post-operative counselling/care, pain management, and optimal circumcision techniques.

\section{Sample size}

The study intended to survey 60 health facilities in three districts of Tanzania. In each facility, we aimed to interview the head of the facility, up to 5 of the rare professional cadres (ratio of 1 health practitioner to 50,000 people using national data) and up to 3 of the remaining cadres. The selection of the health practitioners was done randomly. Rare professional cadres included physicians, assistant medical officers (AMOs), clinical officers (COs), counsellors and anaesthetists.

Professional experience and aims of the study guided the decision making process of the number of health practitioners to be interviewed per cadre. The number of healthcare workers at the selected health facilities was unknown and varied with the level of health facility.

\section{Data processing and analysis}

The questionnaires were double entered by two independent data entry clerks using

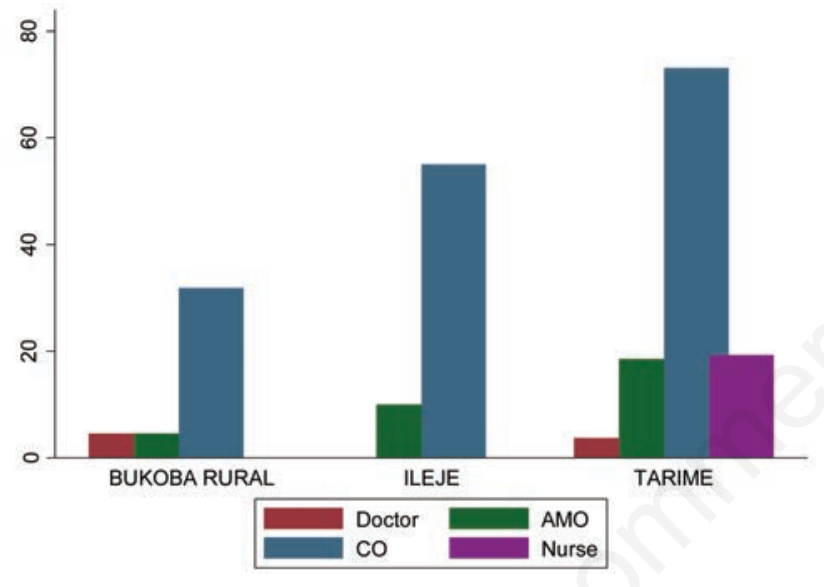

Figure 1. Circumcision providers (doctors, assistant medical officers, clinical officers, nurses) in the districts under study.

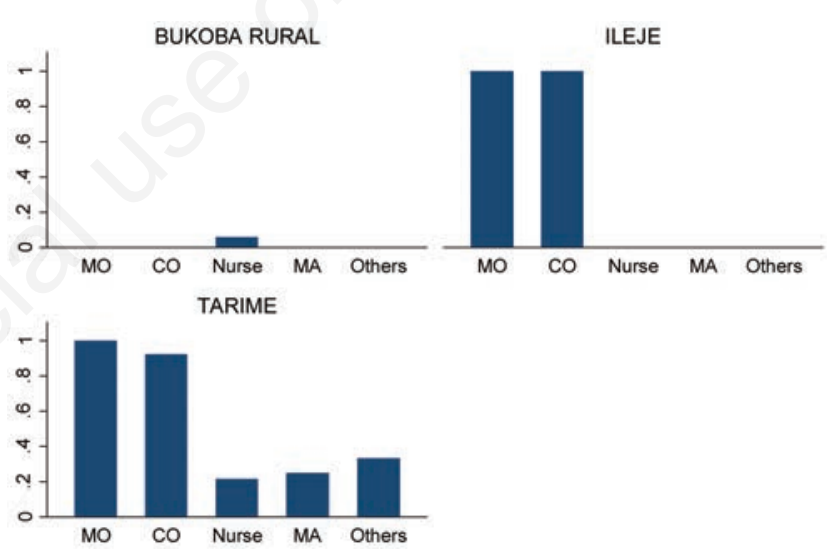

Figure 2. Percentage of health practitioners providing circumcision for the past 12 months arranged by designation (medical officers, clinical officers, nurses, medical attendants, others) and district.

Table 1. Description of the health facilities surveyed.

\begin{tabular}{|c|c|c|c|c|c|c|c|}
\hline \multirow[t]{2}{*}{ Factor } & \multicolumn{2}{|c|}{$\begin{array}{l}\text { Bukoba rural } \\
\text { (Total } \mathrm{n}=22 \text { ) }\end{array}$} & \multicolumn{2}{|c|}{$\begin{array}{c}\text { Ileje } \\
(\text { Total } n=20)\end{array}$} & \multicolumn{2}{|c|}{$\begin{array}{c}\text { Tarime } \\
\text { (Total } n=27)\end{array}$} & \multirow[t]{2}{*}{$\chi^{2}$ (P value) } \\
\hline & n & $\%$ & n & $\%$ & n & $\%$ & \\
\hline \multicolumn{8}{|c|}{ Type of health facility } \\
\hline Hospital & 1 & 4.5 & 2 & 10.0 & 1 & 3.7 & $5.15(0.19)$ \\
\hline Health centre & 6 & 27.3 & 1 & 5.0 & 8 & 29.6 & \\
\hline Dispensary & 15 & 68.2 & 17 & 85.0 & 18 & 66.7 & \\
\hline \multicolumn{8}{|c|}{ Ownership of health facility } \\
\hline Government & 16 & 72.7 & 17 & 85.0 & 13 & 48.2 & $13.5(0.029)$ \\
\hline Faith-based & 4 & 18.2 & 3 & 15.0 & 7 & 25.9 & \\
\hline NGO & 1 & 4.5 & 0 & - & 0 & - & \\
\hline Private & 1 & 4.5 & 0 & - & 7 & 25.9 & \\
\hline \multicolumn{8}{|c|}{ Population of service area } \\
\hline$<10,000$ & 15 & 68.2 & 18 & 90.0 & 16 & 59.3 & $5.4(0.06)$ \\
\hline$\geq 10,000$ & 7 & 31.8 & 2 & 10.0 & 11 & 40.7 & \\
\hline
\end{tabular}

NGO, non-governmental organization. 
Census and Surveys processing System, ${ }^{18}$ cleaned and validated. A descriptive analysis of the data was done using the STATA data analysis software. ${ }^{19}$ Chi square tests were done to compare the similarity of the study districts with respect to type of health facility in the district, ownership, population of the service area, capacity of the district to deliver safe circumcision services and complications reported to the health facilities. The chi-square statistics with its $P$ value is reported where appropriate; when numbers were small, Fisher's exact test was used.

\section{Ethical considerations}

The ethical clearance for the study was obtained from the Medical Research Coordination Committee (MRCC) of the National Institute for Medical Research, Tanzania. All participants were asked to give written informed consent prior to enrolment.

\section{Results}

Sixty nine of 93 (74.2\%) facilities were visited in 3 districts. Of these, $4 / 69(6 \%)$ were hospitals, 15/69 (22\%) were health centres, and 50/69 (73\%) dispensaries. Most of the facilities visited served a population of $<10,000$. Overall, two-thirds of the facilities were owned by the government of Tanzania. In Tarime district, Government of Tanzania significantly owned less facilities than in Bukoba rural and Ileje districts $\left(\chi^{2}=13.5, \mathrm{P}=0.029\right)$ and similarly, facilities in Tarime district significantly served more people than those in Ileje and Bukoba rural districts. However, the type of facilities in the three districts did not differ significantly (Table 1). These facilities had a total of 714 health practitioners (199 males, 515 females). Of these, 5 ( 4 males, 1 female) were doctors, 23 (17 males, 6 females) were AMOs, 88 (68 males, 20 females) were $\mathrm{COs}, 6$ were anesthetists ( 5 males, 1 female), 80 were counsellors ( 24 males, 56 females) and 54 were nursing officers (15 males, 39 females). Others were 157 enrolled nurses (21 males, 136 females) and 301 medical attendants (45 males, 256 females). The four hospitals had 3 doctors, 16 AMOs and $29 \mathrm{COs}$, while the 15 health centres had 1 doctor, 3 AMOs and 17 COs. The 50 dispensaries had 1 doctor, 4 AMOs and $42 \mathrm{COs}$. On average a doctor, AMO or CO, served 8 people per day if they worked in a hos- pital, 38 people per day if they worked in a health centre and 25 people per day if they worked in a dispensary. However, it is worthy to mention that this is not related to the number of MC procedures they performed in a day.

\section{Current capacities of the health facilities}

The three districts did not differ significantly with respect to the available basic surgical facilities (Table 2). Overall, only 6/69 (9\%) had an operating main theatre, $44 / 69$ (64\%) had an operating outpatient minor theatre, $63 / 69$ (91\%) had operating essential surgical equipment and 15/69 (22\%) had functioning emergency equipment. In all three districts, nearly half or less than half of all facilities had reliable water or reliable electricity. Reliable water and electricity did not differ significantly across the three districts. The main source of electricity was the national grid, though in Bukoba rural district, solar energy supplied electrical power to one-fifth of the health facilities surveyed. Running water was mainly provided by a captive source and, to a lesser extent, from water authorities.

Generally, most facilities surveyed in all the three districts did not use autoclave sterilizing

Table 2. Current capacity of the facilities surveyed.

\begin{tabular}{|c|c|c|c|c|c|c|}
\hline \multirow[t]{2}{*}{ Factor } & \multicolumn{2}{|c|}{$\begin{array}{l}\text { Bukoba rural } \\
\text { (Total n=22) }\end{array}$} & \multicolumn{2}{|c|}{$\begin{array}{c}\text { Ileje } \\
(\text { Total } \mathrm{n}=20)\end{array}$} & \multicolumn{2}{|c|}{$\begin{array}{c}\text { Tarime } \\
\text { (Total } n=27)\end{array}$} \\
\hline & n & $\%$ & n & $\%$ & n & $\%$ \\
\hline \multicolumn{7}{|l|}{ Facilities with basic surgical facilities ${ }^{\circ}$} \\
\hline Main operating theatres & 2 & 9.1 & 2 & 10.0 & 2 & 7.4 \\
\hline Outpatient minor theatre & 15 & 68.2 & 9 & 45.0 & 20 & 74.1 \\
\hline Essential surgical equipment & 21 & 95.4 & 18 & 90.0 & 24 & 88.9 \\
\hline Essential emergency equipment & 7 & 31.8 & 2 & 10.5 & 6 & 22.2 \\
\hline Facilities with reliable power & 9 & 40.9 & 7 & 35.0 & 10 & 37.0 \\
\hline Facilities with adequate water supply & 11 & 50.0 & 9 & 47.4 & 13 & 48.2 \\
\hline \multicolumn{7}{|l|}{ STI services } \\
\hline STI services dedicated & 0 & - & 2 & 10.0 & 2 & 7.4 \\
\hline STI services integrated & 22 & 100.0 & 16 & 80.0 & 24 & 88.9 \\
\hline \multicolumn{7}{|l|}{ Counselling and testing for HIV } \\
\hline Dedicated HIV counselling and testing & 9 & 40.9 & 11 & 55.0 & 11 & 42.3 \\
\hline Intergraded HIV counselling and testing & 13 & 59.1 & 8 & 40.0 & 23 & 88.5 \\
\hline \multicolumn{7}{|l|}{ RCH services $^{\circ}$} \\
\hline ANC & 22 & 100.0 & 18 & 90.0 & 27 & 100.0 \\
\hline Under-five services & 20 & 90.9 & 19 & 95.0 & 24 & 88.9 \\
\hline Family planning services & 22 & 100.0 & 18 & 90.0 & 23 & 85.2 \\
\hline Post-natal services & 22 & 100.0 & 18 & 90.0 & 20 & 95.2 \\
\hline \multicolumn{7}{|l|}{ Functioning sterilizing equipment } \\
\hline Autoclave & 4 & 18.2 & 2 & 10.0 & 4 & 14.8 \\
\hline Pressure cooker & 3 & 13.6 & 1 & 5.0 & 11 & 40.7 \\
\hline \multicolumn{7}{|c|}{ Supplies for basic infection prevention (12 months) } \\
\hline Chlorine or appropriate decontaminant & 21 & 91.5 & 19 & 95.0 & 23 & 85.2 \\
\hline Plastic bucket for decontamination & 22 & 100.0 & 19 & 95.0 & 25 & 92.6 \\
\hline Gloves (surgical, examination, cleaning) & 22 & 100.0 & 20 & 100.0 & 27 & 100.0 \\
\hline Waste disposal & 22 & 100.0 & 18 & 90.0 & 26 & 96.3 \\
\hline Facilities providing condoms to public & 20 & 90.9 & 20 & 100 & 22 & 84.6 \\
\hline
\end{tabular}

STI, sexually-transmitted infection; RCH, reproductive and child health; ANC, ante-natal care. ${ }^{\circ}$ People in-charge of health facilities selected more than one response. 
Table 3. Complications of circumcision.

\begin{tabular}{|c|c|c|c|c|c|c|c|}
\hline \multirow[t]{2}{*}{ Factor } & \multicolumn{2}{|c|}{$\begin{array}{c}\text { Tarime } \\
\text { (Total } n=107 \text { ) }\end{array}$} & \multicolumn{2}{|c|}{$\begin{array}{l}\text { Bukoba rural } \\
\text { (Total } n=49 \text { ) }\end{array}$} & \multicolumn{2}{|c|}{$\begin{array}{c}\text { Ileje } \\
\text { (Total } n=39 \text { ) }\end{array}$} & \multirow[t]{2}{*}{$\chi^{2}$ (P value) } \\
\hline & n & $\%$ & n & $\%$ & n & $\%$ & \\
\hline \multicolumn{8}{|c|}{ Complication arising elsewhere not from clinical settings ${ }^{\circ}$} \\
\hline Excessive bleeding & 77 & 69.4 & 20 & 40.8 & 0 & - & $57.2(<0.001)$ \\
\hline Infections & 73 & 69.4 & 23 & 46.9 & 4 & 10.3 & $41.2(<0.001)$ \\
\hline Disfigurement & 75 & 67.6 & 22 & 44.9 & 4 & 10.3 & $38.8(<0.001)$ \\
\hline Impotence & 73 & 65.8 & 23 & 46.9 & 4 & 10.3 & $35.9(<0.001)$ \\
\hline Other & 35 & 31.5 & 2 & 4.1 & 2 & 5.1 & $22.7(<0.001)$ \\
\hline \multicolumn{8}{|c|}{ Complication arising from clinical settings ${ }^{\circ}$} \\
\hline Excessive bleeding & 7 & 6.3 & 4 & 8.2 & 0 & - & $3.1(0.216)$ \\
\hline Infections & 5 & 4.5 & 4 & 8.2 & 0 & - & $3.6(0.187)$ \\
\hline Disfigurement & 5 & 4.5 & 1 & 2.0 & 0 & - & $2.2(0.331)$ \\
\hline Impotence & 5 & 4.5 & 4 & 8.2 & 0 & - & $3.4(0.187)$ \\
\hline Other & 4 & 3.6 & 1 & 2.0 & 0 & - & $1.6(0.452)$ \\
\hline
\end{tabular}

${ }^{\circ}$ Health practitioners selected more than one response.

equipment. However, facilities in Tarime district significantly reported the use of pressure cooker as sterilizing equipment more than facilities in Bukoba rural and Ileje districts $\left(\chi^{2}=9.87, \mathrm{P}=0.011\right)$.

Sexually-transmitted infections (STIs) and voluntary counselling and testing (VCT) services were available in almost all the health facilities surveyed. These services were integrated into the outpatient department. Reproductive and child health (RCH) services such as ante-natal clinic care [67/69 (97\%)], family planning $[63 / 69(91 \%)]$, post-natal services [60/69 (87\%)] and services to children aged less than 5 [63/69 (91\%)] were common services offered in almost all facilities. About 37/46 (80\%) of the government-owned facilities visited had all four essential supplies required for basic infection prevention, i.e. gloves, basin, chlorine and waste disposal. Twenty nine out of forty six (64\%) government facilities visited provided condoms, HIV counselling and testing, and STI services to the community. There was no correlation between the number of skilled staff available and the number of surgeries done in the last 12 months (correlation between staff and surgeries, 49\%). Approximately, 13/14 (90\%) of the faith-based facilities visited had all four essential supplies (gloves, basin, chlorine and waste disposal) for infection prevention. Two-thirds (8/14) of all the faith-based facilities visited did not provide condoms to the community. While additional 4/14 (30\%) health facilities were providing STI, HIV counselling and testing services, and condoms. For faith-based health facilities, there was a strong correlation between the number of skilled staff available and the number of surgeries done in the last 12 months (correlation between staff and surgeries, 92\%).

\section{Facilities providing circumcision services}

About 41/69 (59\%) of the health facilities surveyed were providing MC services. Significantly, more facilities 22/27 (82\%) in Tarime district were providing MC services compared to facilities in Bukoba rural 8/22 (36\%) and Ileje 11/20 (55\%) districts $\left(\chi^{2}=10.46, \mathrm{P}=0.005\right)$.

Overall, fewer facilities had records on circumcision procedures done: $3 / 11$ (27.3\%) in Ileje, 6/22 (27.3\%) in Tarime, and 2/8 (25.0\%) in Bukoba rural districts.

Most of the circumcisions were conducted by $\mathrm{COs}$ and were done either in outpatient minor theatre or elsewhere. In Tarime district nurses performed circumcision procedures in addition to AMOs and doctors (Figure 1).

In Tanzania, COs are high school graduate who have undergone a diploma course in clinical training, while AMOs are COs who have received 3 years of additional clinical training after their clinical diploma. These two medical cadres form the bulk of clinical health practitioners in most hospitals, health centres and dispensaries. Overall, 63/69 (91\%) of the health facilities felt that they would be capable of providing circumcision services if it was promoted in their area. Similarly, 66/69 (96\%) of the health facilities reported that they would be able to increase the number of circumcisions performed if they had additional equipment and instruments and more staff trained on how to perform MC. To improve circumcision services, facilities were recommended to have: reliable electrical power, medicines, recruitment and training of staff, surgical protective gear, and availability of a procedure room. Other requirements were sterilizer, surgical bed and adequate water supply. Most of the health facilities - 58/69 (84\%) - suggested that circumcision should be included into the National Health Insurance Fund cover.

\section{Competence of the providers}

Two hundred and three health practitioners (53 males, 150 females) were interviewed from the 3 study districts. Of these, 113/203 (56\%) were from Tarime, 50/203 (24.6\%) and 40/203 (19.7\%) were from Bukoba rural and Ileje districts, respectively. The majority of the respondents [130/203 (64\%)] was composed by nurses. Of those interviewed, 163/203 (80\%) had performed circumcision procedure for more than 5 years. Providers in Ileje and Bukoba had practiced medicine significantly longer than those in Tarime $\left(\chi^{2}=12.9\right.$, $\mathrm{P}=0.045)$. Conversely, practitioners in Tarime had significantly performed more circumcisions than those in Ileje and Bukoba rural $\left(\chi^{2}=29.11, P<0.001\right)$. In Bukoba rural, circumcision was mainly done by nurses, while in Ileje it was mainly done by medical officers, AMOs and COs. In Tarime, circumcision was done by all health practitioners including medical attendants, lab technicians and anesthetists, most of whom had no formal training but learned through observation (Figure 2).

\section{Complications of male circumcision}

Complications observed by health practitioners were excessive bleeding, infections, disfigurement and erectile dysfunction. The three districts differed significantly in terms of magnitude and type of complications observed $\left(\chi^{2}=57.22, P<0.001\right)$. Most complications were reported by practitioners from Tarime. This could be attributed to traditional circumcision practices (Table 3).

Complications were also reported in clinical-based circumcision, though at a lesser magnitude compared to traditional circumcisions. In Ileje district, there were no reported 
cases of complication arising from circumcisions done in clinical setting.

This may be because all circumcision procedures were done by medical officers or $\mathrm{COs}$ only, unlike what reported in Tarime and Bukoba rural districts.

\section{Male circumcision training and challenges}

Only 50 (25\%) of the 203 respondents reported to have received training on MC and 41/50 (82\%) of those were from Tarime district. Of those reporting to have been trained, $22 / 50$ (44\%) were trained in college and 28/50 (56\%) received on-job training. Overall, 190/203 (94\%) of the practitioners interviewed said they will benefit from additional circumcision training. The major challenges reported by respondents in providing circumcision services to a large number of males in health facilities were lack of equipment [97/190 (51\%)], lack of enough trained practitioners [89/190 (47\%)], and inadequate space for circumcision procedures [5/190 (2\%)]. The majority of the untrained health practitioners did not perform circumcision. Only 12/46 (26\%) of practitioners who reported to have never received any $\mathrm{MC}$ training reported to perform MC services.

\section{Discussion}

Our study relied heavily on reported information and what we could observe at the time of the survey. For example, the method we used to assess complications was based on what respondents could remember and therefore, it could be affected by recall biases. Competence of the health providers was reported rather than observed, as there were no circumcision procedure going on at the time of the survey. The best method would be for a doctor to observe MC procedures and follow-up patients to assess healing and complications like the study conducted in Bungoma, Kenya. ${ }^{16}$

Eighty percent of the government health facilities and $90 \%$ of the faith-based organizations (FBOs) had all four essential supplies required for basic infection prevention, i.e. gloves, basin, chlorine and waste disposal, which are important as part of MC scale up.

Forty three percent of health practitioners reported to be performing the MC procedure; half of these providers have never been formally trained on MC. When this study was conducted, there were neither guidelines nor policy document guiding MC practices. Findings from this study led to the development of a national strategy for scaling up MC for HIV prevention. In the new guidelines, nurses are allowed to provide circumcision services.
A similar situation where practitioners lacked knowledge and training, proper instruments and supplies at most health facilities was reported in a study carried out in Bungoma district, Kenya. ${ }^{16}$ Therefore, it is important that the policy in Tanzania defined the minimum quality of care to be provided in MC. Service providers will need to be assessed for competency, and facilities will be required to meet specific criteria as set by the Medical Council..$^{20}$

In this study, some facilities visited had sterilization equipment and basic infection prevention facilities, and most facilities had basic surgical equipments. This suggests that the roll-out of circumcision services is almost ready. However, more practitioners need to be trained and facilities provided with the required equipment. Lack of equipment and inadequate training of health practitioners has also been reported in other countries. ${ }^{16}$

Moreover, there was a strong correlation between the number of surgeries done in the last 12 months and the number of staff available in facilities owned by FBOs, unlike what reported in government-owned facilities. This lack of correlation may either be due to lack of staff motivation or inaccurate documentation of surgeries done.

Healthcare workers were over, some of the health facilities did not have clinicians and were run by nurses and others had alarming understaffing. Our finding is consistent with that from the Bureau of Statistics Survey of 2006 where in most parts of Tanzania one doctor served 10,000 people. ${ }^{21}$ This area still remains a major challenge despite the efforts to recruit and train healthcare workers. Therefore, where appropriate, we recommend tasks to be delegated to less specialized health workers (task shifting) or to be shared with these less specialized workers. ${ }^{20}$

The successful use of less specialized health workers (e.g. nurses and COs) to perform more complex clinical and surgical procedures is well-documented in various countries..$^{15}$ There are many examples of this type of delegation for delivering a range of health services, including those for HIV. ${ }^{22}$ In a number of highincome countries, such as Australia, UK, and the USA, the role of nurses has been extended in some settings to include the prescription of routine medication, and people living with HIV/AIDS have been empowered to participate in the management of their own chronic condition and to support others as part of expert patient programs. ${ }^{22-26}$ Task-shifting of various kinds is also currently being implemented in some resource-constrained countries as a response to acute shortages of human resources for health and particularly for generalized HIV epidemics. In Malawi and Uganda, the basic care package for people living with
HIV/AIDS has been designed to be delivered by non-specialist doctors or nurses supported by community health workers and people living with HIV/AIDS. Similarly, Ethiopia has implemented a plan to hire community health workers to expand the current workforce delivering HIV services.

Experience has also shown that appropriately trained non-physician providers can safely conduct surgical procedures under local anaesthesia. ${ }^{15}$ Specifically, it has been successfully demonstrated that well-trained staff (including COs) can be used to perform circumcision. ${ }^{4}$ Thus, in order to scale up the availability of MC services, it is recommended that Tanzania should identify non-physician providers (like COs and nurses) who can be trained to perform this procedure. ${ }^{20}$

\section{Conclusions}

In this study, we found that a large proportion of facilities visited had sterilization equipment and basic infection prevention facilities, staff was willing to be trained and most facilities had basic surgical equipments, suggesting that there is capacity to scale up MC in Tanzania. However, in order to meet the increased demand for MC services as a result of roll out, more practitioners need to be trained and facilities will need more supplies and medication for circumcision services.

\section{References}

1. Siegfried N, Muller M, Deeks J, et al. HIV and male circumcision - a systematic review with assessment of the quality of studies. Lancet Infect Dis 2005;5:165-73.

2. Weiss HA, Quigley MA, Hayes RJ. Male circumcision and risk of HIV infection in subSaharan Africa: a systematic review and meta-analysis. AIDS 2000;14:2361-70.

3. Auvert B, Taljaard D, Lagarde E, et al. Randomized, controlled intervention trial of male circumcision for reduction of HIV infection risk: the ANRS 1265 Trial. PLoS Med 2005;2:e298.

4. Bailey R, Moses CS, Parker CB, et al. Male circumcision for HIV prevention in young men in Kisumu, Kenya: a randomised controlled trial. Lancet 2007;369:643-56.

5. Gray RH, Kigozi G, Serwadda D, et al. Male circumcision for HIV prevention in men in Rakai, Uganda: a randomised trial. Lancet 2007;369:657-66.

6. Clark S, Gerber W, Fua I. Male circumcision: current epidemiological and field evidence. Program and policy implications of 
male circumcision for HIV prevention and reproductive health. Conference report, 2002 Sept 18-19, Washington, USA. Washington, DC: US Agency for International Development and AIDSMark; 2003. pp 1-35.

7. Wiswell TE, Hachey WE. Urinary tract infections and the uncircumcised state: an update. Clin Pediatr 1993;32:130-4.

8. Cook LS, Koutsky LA, Holmes KK. Circumcision and sexually transmitted diseases. Am J Public Health 1994;84:197201.

9. Nasio JM, Nagelkerke NJ, Mwatha A, et al. Genital ulcer disease among STD clinic attenders in Nairobi: association with HIV1 and circumcision status. Int J STD AIDS 1996;7:410-4.

10. Barclay L. Circumcision significantly reduces risk of HIV transmission. Medscape 2006. Available from: http:// www.medscape.com/viewarticle/549547

11. American Academy of Pediatrics. Report of the task force on circumcision. Pediatrics 1989;84:761.

12. Dodge OG, Kaviti JN. Male circumcision among the peoples of East Africa and the incidence of genital cancer. E Afr Med J 1965;42:98-105.

13. Agarwal SS, Sehgal A, Sardana S, et al. Role of male behaviour in cervical carcinogenesis among women with one lifetime sexual partner. Cancer 1993;72:1666-9.

14. Williams BG, Lloyd-smith J0, Gouws E, et al. the potential impact of male circumcision on HIV in sub-Saharan Africa. PLoS
Med 2006;3:e262.

15. WHO, UNAIDS. New data on male circumcision and HIV prevention: policy and programme implications. In: Proceedings of the WHO/UNAIDS technical consultation on male circumcision and HIV prevention: research implications for policy and programming, 2007 March 6-8, Montreux, France. Geneva: WHO ed.; 2007. Available from: http:/www.who.int/hiv/pub/malecircumcision/research_implications/en/inde x.html

16. Robert CB, Omar E, Stephanie R. Male circumcision for HIV prevention: a prospective study of complications in clinical and traditional settings in Bungoma, Kenya. B World Health Organ 2008;86:669-77.

17. Wambura M, Mwanga JR, Mosha JF, et al. Acceptability of medical male circumcision in traditionally circumcising communities in Northern Tanzania. BMC Public Health 2011;11:373.

18. United States Census Bureau. Census and survey processing system (CSPro). Washington, DC: US Census Bureau ed.; 2012. Available from: http://www.census. gov/population/international/software/cspr o/ Accessed: 22/01/2013.

19. STATA Corp. Stata statistical software: release 8 . College Station, TX: StataCorp LP ed.; 2003. Available from: http://www. joplink.net/prev/200901/ref/08-013.html Accessed: 22/01/2013.

20. WHO, UNAIDS. Progress in male circumcision scale-up. Country implementations update. Geneva: WHO ed.; 2009. Available from: www.malecircumcision.org/publications/documents/Country_experiences_in _scale-up_in_Eastern_and_Southern_ Africa_06.09.09.pdf. Accessed 01/03/2011.

21. NBS and Macro International Inc. Tanzania service provision assessment survey 2006. Key findings on HIV/AIDS. Dar es Salaam: National Bureau of Statistics and Macro International Inc. ed.; 2007.

22. Samb B, Celletti F, Holloway J, et al. Task shifting: an emergency response to the health workforce crisis in the era of HIV. Lessons from the past, current practice and thinking. New Engl J Med 2007;357: 2510-4.

23. Laurant M, Reeves D, Hermens R, et al. Substitution of doctors by nurses in primary care. Cochrane Db Syst Rev 2005;2: CD001271.

24. Hongoro C, McPake B. How to bridge the gap in human resources for health. Lancet 2004;364:1451-6.

25. Lewis CE, Miramontes $H$. Nurse practitioners in rural California and AIDS. $\mathrm{J}$ of Assoc Nurse AIDS C1999;10:39-42.

26. Kober K, Van Damme W. Expert patients and AIDS care. A literature review on expert patient programmes in highincome countries, and an exploration of their relevance for HIV/AIDS care in lowincome countries with severe human resource shortages. Antwerp: Institute of Tropical Medicine ed.; 2006. 